\title{
Effects of posture and squatting on the dynamics of micturition: response to Bush and Liedl
}

\author{
Jay Iyer • Ajay Rane
}

Published online: 20 February 2015

(C) The International Urogynecological Association 2015

Dear Editor,

We thank Drs Bush and Liedl [1] for their detailed and analytical response to our article [2] and would like to reply as follows:

1. The biomechanical explanation advanced by the authors correlates well with our research question and is complementary to our conclusions.

2. One of the primary drivers of this research was to develop a mechanism to construct a user-friendly and inexpensive device that would confer the health benefits of squatting to the population at large, without the actual need to squat (the Duneze device mentioned in our article).

\section{References}

1. Bush MB, Liedl B (2015) Effects of posture and squatting on the dynamics of micturition. Int Urogynecol J. doi:10.1007/s00192-015-2643-7

2. Rane A, Iyer J (2014) Posture and micturition: does it really matter how a woman sits on the toilet? Int Urogynecol J 25:1015-1021. doi: $10.1007 / \mathrm{s} 00192-013-2284-7$
J. Iyer $(\bowtie) \cdot$ A. Rane

The Townsville and Mater Hospitals, Townsville, Queensland, Australia

e-mail: drsgiyer2002@yahoo.co.uk 